\title{
Discours
}

Revue de linguistique, psycholinguistique et

informatique. A journal of linguistics, psycholinguistics

and computational linguistics

$5 \mid 2009$

Varia

\section{On the correlation between discourse frequency and structural complexity in markedness theory}

\section{Regina Pustet}

\section{OpenEdition}

\section{Journals}

\section{Electronic version}

URL: http://journals.openedition.org/discours/7683

DOI: $10.4000 /$ discours.7683

ISSN: $1963-1723$

\section{Publisher:}

Laboratoire LATTICE, Presses universitaires de Caen

\section{Electronic reference}

Regina Pustet, « On the correlation between discourse frequency and structural complexity in markedness theory », Discours [Online], 5 | 2009, Online since 04 December 2009, connection on 19 April 2019. URL : http://journals.openedition.org/discours/7683 ; DOI : 10.4000/discours.7683

\section{(c) $(1)(9)$}

Discours est mis à disposition selon les termes de la licence Creative Commons Attribution - Pas d'Utilisation Commerciale - Pas de Modification 4.0 International. 


\author{
On the correlation between discourse frequency \\ and structural complexity in markedness theory \\ Regina Pustet \\ University of Munich
}

\begin{abstract}
:
Markedness is commonly regarded as one of the fundamental organizing principles of human language. However, the reasons for the existence of markedness phenomena continue to be controversial, if not to say obscure. The analysis of discourse corpora from three genetically unrelated languages which is conducted in this study suggests that at least one of the decisive aspects of markedness, namely, the correlation between frequency and structural complexity, can be understood as a necessary consequence of the general statistical regularities disclosed in Zipf's discourse-based model of language.
\end{abstract}

\title{
Keywords:
}

Markedness, discourse frequency, structural complexity of linguistic items, Zipf's Law

\section{The hypothesis: markedness relations as a corollary of Zipf's model of language}

1 Markedness can be regarded as one of the main organizing principles of human language. Ever since its discovery by Prague School scholars, markedness has figured as one of the central topics in language theory. The initial formulations of markedness theory were exclusively concerned with phonology (e.g. Trubetzkoy, 1931), but before long, the concept was applied to morphology, syntax, and semantics as well (e.g. Jakobson, 1932/1984a, 1936/1984b, 1939/1984c). Taking the Prague School version of markedness theory as an inspiration, Greenberg (1966) set out to track down markedness phenomena at various levels of language description, particularly in morphosyntax, to the effect that in today's literature on the subject, morphosyntactic markedness attracts at least as much attention as phonological markedness. Although the concept of markedness, as developed by Greenberg, has been elaborated on substantially in the works of Andersen (e.g. 1972), Battistella (e.g. 1996), Croft (e.g. 1990, 1991), Givón (e.g. 1995), Shapiro (e.g. 1983, 1991), and others, Greenberg (1966), in essence, still presents the most comprehensive catalog of markedness criteria available to date. Despite the extensive research on markedness which has been conducted since Greenberg's pioneering article, no satisfactory answer to the question about the origins of markedness phenomena has been provided.

2 The numerous manifestations of markedness are not restricted to language -- they also surface in neighboring disciplines such as cognitive science, psychology, and neurology. Consequently, any attempt at explaining the phenomenon of markedness in its entirety will be an endeavor of considerable complexity. The present study does not claim to provide an exhaustive discussion of markedness and its possible underpinnings. The specific aim of this paper is exploring one particular aspect of morphosyntactic markedness in greater depth, namely, the correlation between structural complexity, i.e. length, of linguistic items and their frequency of occurrence in discourse. Both variables have been generally recognized as essential components of the phenomenon of markedness: the structurally less complex member of a linguistic opposition tends to be the more frequent one in discourse.

3 An important source of further insights in dealing with the correlation between structural complexity and discourse frequency in markedness theory has been around for quite a 
while: Zipf-style corpus studies. Although G. K. Zipf (1902-1950) was neither the first nor the last scholar to carry out frequency-based discourse analyses, he remains the most influential proponent of such linguistic approaches to date. Taking linguistic discourse as a starting point of his empirical investigations, Zipf discovered a fundamental statistical law ("Zipf's Law") which later turned out to be effective in a multitude of disciplines in the physical, biological, and behavioral sciences, and is recognized today as part of the set of statistical regularities referred to as power laws. Zipf himself has provided ample evidence for the validity of his statistical correlations in extra-linguistic domains as diverse as geography, politics, economy, art, biology, and psychology. For instance, cities, towns, or other communities can be ranked according to population size, just like linguistic items can be ranked according to their structural complexity, i.e. according to the number of phonemes they are composed of. Table 1, adapted from Gell-Mann (1994: 94), and the resulting graph given in Figure 1, exemplify a Zipfian distribution by means of population figures for U.S. cities obtained from the 1990 World Almanac. ${ }^{1}$

Table 1. Populations of U.S. cities from the 1990 World Almanac (Gell-Mann 1994:94): figures

\begin{tabular}{|l|l|l|}
\hline rank & city & population (1990) \\
\hline 1 & New York & 7.322 .564 \\
\hline 7 & Detroit & 1.027 .974 \\
\hline 13 & Baltimore & 736.014 \\
\hline 19 & Washington, D.C. & 606.900 \\
\hline 25 & New Orleans & 496.938 \\
\hline 31 & Kansas City, Mo. & 434.829 \\
\hline 37 & Virginia Beach, Va. & 393.089 \\
\hline 49 & Toledo & 332.943 \\
\hline 61 & Arlington, Texas & 261.721 \\
\hline 73 & Baton Rouge, La. & 219.531 \\
\hline 85 & Hialeah, Fla. & 188.008 \\
\hline 97 & Bakersfield, Ca. & 174.820 \\
\hline
\end{tabular}

4 The most striking characteristic of a Zipfian distribution is its regular hyperbolic shape, which is also illustrated by the rank-based analyses of the linguistic data compiled for the purpose of this study; cf. Figures 2, 3, and 4.

Figure 1. Populations of U.S. cities from the 1990 World Almanac (Gell-Mann 1994:94): graphics; on ordinate: population figures in millions, on abscissa: rank based on population

\footnotetext{
${ }^{1}$ In a bona fide Zipfian analysis, positions in the ranking scale, which are presented in column 1 in table 1 , would not be skipped, as is done in this case by Gell-Mann for purposes of simplification. Thus, for instance, cities ranking between positions 1 and 7 (New York and Detroit) would also be included in the investigation.
} 


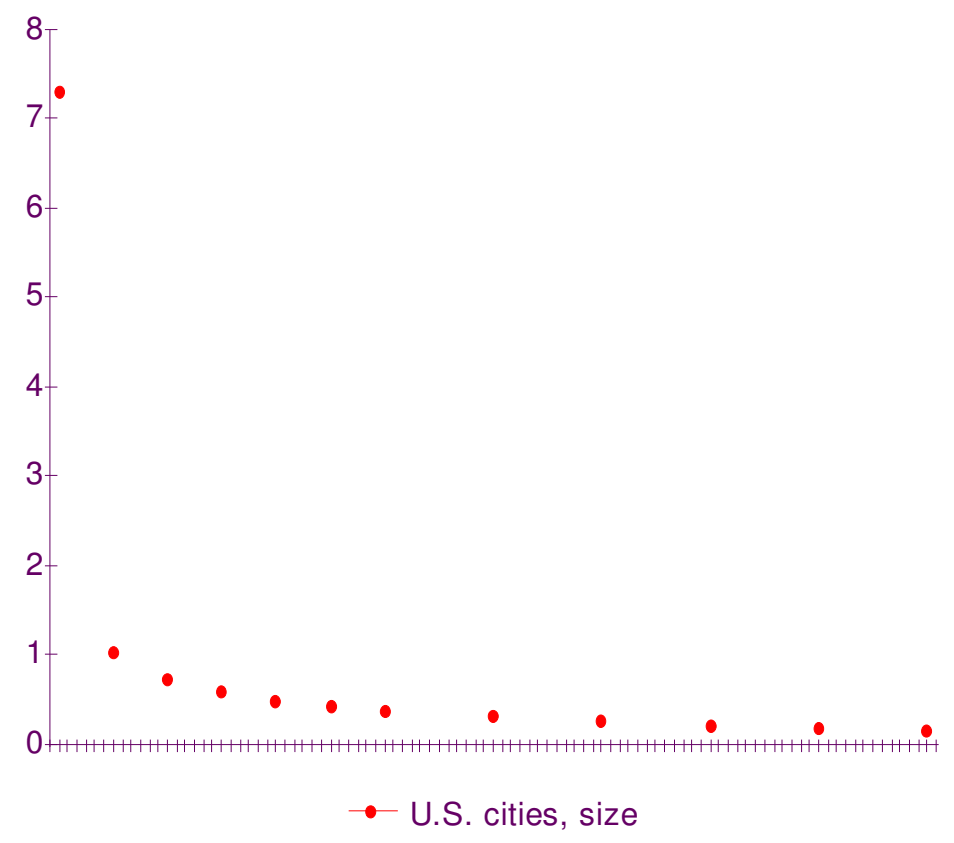

5 Not every Zipf-style analysis employs ranking. Another Zipfian method targets correlations between the variables of structural complexity and frequency of occurrence. In Zipf $(1949 / 1965 b)$ it is shown that the cities, towns, and other communities in a given geographic area which exhibit the highest population figures -- i.e. those which occupy the highest ranks in the rank-based type of analysis mentioned above -- are also the ones which occur least frequently, just like the phonetically most complex units in a given stretch of linguistic discourse are the least frequent. Zipf's model of language (Zipf, 1935/1965a, 1949/1965b) is mainly known for the axiom that the formal complexity of a given linguistic item is in inverse proportion to its discourse frequency ("the shorter, the more frequent"). For linguistic items and communities, the same correlation between structural complexity and frequency holds: in a matrix in which values for both variables are entered, the values for structural complexity decrease gradually as the values for frequency increase in such a way that, as in the case of rank-based analyses, hyperbolic structures are obtained.

6 Linking markedness with Zipf's model of language culminates in the hypothesis that the existence of markedness phenomena is the necessary consequence of Zipfian principles. To achieve this, however, a slight modification of Zipf's analytical method is required (cf. section 3). Given the possibility of tracing markedness back to general statistical laws, one might feel tempted to regard the concept of markedness as superfluous and outmoded. This is, however, not the conclusion proposed in the present study, which merely aims at providing an explanatory background for a central subdomain of markedness by tying it in with higher-order quantitative principles. The extreme views articulated in Haspelmath (2006) are not supported in this paper.

7 It should be noted that the research conducted in this study is empirical at the most basic level conceivable and entirely theory-independent. Theoretical constructs, no matter what framework they may originate in, are not needed here. The method of data compilation used is confined to (a) counting linguistic items in the discourse corpora investigated and (b) counting the phonemes that each of these items is composed of. Such analyses are replicable for any discourse corpus of any language, and the results can be expected to be fairly similar in all cases. 


\section{Morphosyntactic markedness}

8 In this study, no attempt will be made to summarize the vast literature on markedness in every detail -- for an exhaustive overview that covers the subject up to the mid-1990s the reader is referred to Battistella $(1990,1996)$.

9 There is no unified theory of markedness so far (Battistella 1990, 1996); research in this area has not only spawned a multitude of different theoretical models but has also found a wide range of different applications. At the core of the concept of markedness lies the idea that there is some kind of asymmetry in the formal, distributional, semantic, cognitive etc. properties of linguistic units which are in some kind of contrast. Such natural contrasts are referred to as oppositions. But this definition of markedness is vague enough to render the concept universally viable and thus, possibly, more or less trivial. Thus, it does not come as a surprise that the notion of markedness has been used outside of linguistics, for instance, in poetry, anthropology, music, and religion. To illustrate such extensions of the concept of markedness, Battistella (1996: 18, based on McCawley, 1985) cites the idea that "belief in a certain type of supreme being is culturally unmarked, while other options (atheism, agnosticism, belief in a nonprototypical supreme being) are marked". Such interpretations of markedness will not be the subject of the present study, although the possibility that they point to general principles of cognitive organization cannot be ruled out.

10 Morphosyntactic markedness theory focuses on the more or less systematic co-occurrence of certain properties of grammatical or lexical items, or other units of linguistic organization. Many of these correlations are not only encountered at the intra-linguistic, but at the cross-linguistic level as well (cf. in particular Croft, 1990). Research on morphosyntactic markedness was initiated by Greenberg (1966). Although it may be true that none of the diagnostics of morphosyntactic markedness is utilized in all treatises on the topic that have accumulated ever since, Greenberg's catalog of morphosyntactic markedness criteria not only set the standards for all subsequent work in this area. Despite the vastness of the literature on markedness available today, Greenberg's rich list of criteria is not outdated; it can still be taken as defining the essence of morphosyntactic markedness theory. Greenberg (1966) deals with phenomena such as "contextual neutralization", i.e. the fact that in some contextual environments, only one member of a given opposition of linguistic items appears; with "syncretization", i.e. the fact that the number of categorical subdistinctions in the members of oppositions may differ; with "morphological irregularity", i.e. the fact that the number of allomorphs that members of oppositions show may differ, etc. However, the markedness criteria which are of immediate interest in the context of the present study are \#1 and \#8 in Greenbergs list:

Greenberg \#1: zero marking (Greenberg, 1966: 26f.). In a binary opposition of linguistic items, it is often the case that one member (the marked member) is overtly marked, while the other member (the unmarked member) receives zero expression.

Greenberg \#8: discourse frequency (Greenberg, 1966: 31ff.). In a given opposition of linguistic items, one member tends occur more frequently in discourse. The more frequent member is referred to as unmarked.

11 Although so far, there is no explicit consensus on the relative importance of individual markedness diagnostics for defining the concept as a whole, four criteria have undeniably received more attention than others, and are therefore -- possibly -- more fundamental. The criteria in question are discourse frequency, structural complexity, semantic complexity, and cognitive complexity (for a similar weighting of markedness criteria, cf. Moravcsik \& Wirth 1986).

12 The basic claim of markedness theory is that there is an overwhelming tendency for the relevant criteria to coincide in such a way that that member of a binary opposition which is structurally more complex according to the markedness criterion Greenberg \#1, i.e. the member which is not zero-marked, will, more likely than not, exhibit lower discourse 
frequency, less syncretization, less morphological irregularity, etc. than the other member. Greenberg (1966) emphasizes the special importance of discourse frequency as one of the correlates of markedness. Today, the role of discourse frequency as one of the most focal components of markedness theory has been acknowledged (e.g. Andersen, 1989; Croft, 1990, 1991; Givón, 1995). In equating commonness or frequency with unmarkedness on the one hand, and with naturalness on the other, Lass (1980: 42-44) goes one step further and recommends abandoning the terms markedness and unmarkedness, since the latter, in his logic, are covered by the more basic notion of naturalness.

13 Establishing markedness relations requires a common denominator that somehow connects the linguistic elements in question so that they can be said to form natural contrasts, or oppositions. In much of Greenberg's work, the grammatical paradigm creates the notional coherence between linguistic items that provides the basis for investigating markedness relations. Thus, any grammatical elements standing in a paradigmatic relationship to each other, i.e. in a relationship of mutual exclusion within a given morphosyntactic position, such as markers for singular vs. plural, qualify as candidates for markedness studies. One of the innovations suggested by post-Greenbergian markedness theory is the extension of the notion of morphosyntactic markedness beyond individual grammemes and lexemes to constructions (Comrie, 1986; Croft, 1990, 1991, 2001; Givón, 1991, 1995) and even larger units of linguistic organization, such as clause types and discourse types (Givón, 1991, 1995). Further, in contemporary markedness theory, markedness contrasts are not required to be binary -- for instance, a triple contrast, as exemplified by the distinction of singular vs. dual vs. plural, can also be dealt with within the framework of markedness theory (Croft, 1990: 66).

14 Greenberg's list includes a single markedness criterion that pertains to the structural makeup of linguistic items, namely, the criterion of zero expression. In subsequent approaches to markedness the criterion of structural complexity has been modified: the unmarked member of a structurally defined markedness relation does not necessarily have to be zero-marked to be classed as unmarked. It also counts as an instance of structural asymmetry if both members of an opposition of linguistic categories are overtly expressed in such a way that one of the markers involved is structurally less complex than the other. As an example of such a structural constellation, Greenberg (1966: 27) cites the contrast between the English lexemes author- $\varnothing$ and author-ess. Thus, zero marking merely is the extreme manifestation of lack of structural complexity.

15 Markedness theory has been integrated into the generative framework as well. However, as Chomsky's approach evolved over the decades, so did the concept of markedness which is employed in generative language theory. Markedness in early generative theory, insofar as it served to motivate phonological rules (Chomsky \& Halle, 1968), can be regarded as a direct continuation of the approach to markedness which had been initiated by Jakobson and Trubetzkoy. However, starting with its application to syntax, as in Chomsky (1980), generative markedness has been transformed into a theory-internal concept that has become somewhat dissociated from its roots, which are to be sought in empirically observable symptoms such as the systematic interrelatedness of discourse frequency, structural complexity, and semantic complexity. Since the present study exclusively deals with such symptoms of markedness, generative markedness will not be considered in greater detail in this paper. This also goes for Optimality Theory (Prince \& Smolensky, 1993), a formal theory of language which rests on the generative interpretation of markedness.

16 An important insight of current markedness theory is that certain markedness patterns might be universal rather than language-specific. This possibility is envisaged in Greenberg (1966) already, and has been elaborated on especially in Croft (1990). From the perspective of the enormous theory-building potential that inheres in them, however, cross-linguistic approaches to markedness are still in their infancy.

17 In applying Greenbergian markedness theory to language data, it should be kept in mind that the correlations between variables such as discourse frequency and structural complexity are strong but certainly not without exceptions. This fact is often glossed over by the practice of 
devoting more discussion space to data that support markedness theory than to counterexamples. Of the categories of singular and plural, the former is considered the less marked. Nevertheless, the verbal person markers for the third person present tense in English reverse the prediction made by Greenberg \#1, which concerns structural complexity: the third person present singular is coded by means of the affix $-s$, while the third person present plural is zero-marked. In Japanese, the case marker $g a$ is predominantly associated with the coding of the transitive agent (A) and the intransitive subject (S), while the element $o$ serves to code the transitive patient (P), a function which it shares with two additional Japanese case markers (Hinds, 1988: 192-194). S/A markers, however, are unmarked vis-à-vis $\mathrm{P}$ markers on at least one markedness parameter, namely, discourse frequency. It can be assumed that in any language, S/A markers have higher discourse frequency than $\mathrm{P}$ markers. Nevertheless, with respect to the parameter of structural complexity, the Japanese case markers $g a$ and $o$ behave in such a way that higher frequency is paired with higher structural complexity, and lower frequency with lower structural complexity. In the light of such examples, which are certainly not exceptional, neither in Japanese nor in any other language, markedness must be viewed as an organizational feature of human language which is strong but not pervasive.

\section{The correlation between structural complexity and discourse frequency: empirical data}

18 Zipf's fame in linguistics, for the most part, derives from the fact that he discovered the formula "the higher the discourse frequency of a linguistic item, the shorter it will be" (Zipf, 1935/1965a, 1949/1965b), which has, by now, been tested on a vast number of languages of all kinds of genetic affiliations. Empirical data that illustrate this correlation between discourse frequency and structural complexity, which is known as the law of abbreviation, are given below in this section. Like markedness, the law of abbreviation constitutes a very noticeable intra-linguistic and cross-linguistic tendency rather than an absolute rule. Thus, in any language, there are, presumably, counterexamples to the law of abbreviation, that is, high-frequency items which are phonemically complex, and low-frequency items which are phonemically simple. the law of abbreviation, however, is far more comprehensive than markedness theory since it applies to language systems in their totality, rather than to specific oppositions of linguistic items only. That is to say, the law of abbreviation will, by and large, hold for any pair, triplet, etc. of linguistic items in a given language, regardless of whether the latter are members of an opposition, that is, connected by a paradigmatic, semantic, or otherwise defined relationship, as is the case with linguistic items participating in a markedness relation. It so happens that the law of abbreviation and the observation that the markedness criteria Greenberg \#1 (structural complexity) and Greenberg \#8 (discourse frequency) are interdependent describe precisely the same correlation of linguistic variables. But if the overwhelming majority of random pairings of linguistic items within a given language comply with the law of abbreviation, the concept of markedness, insofar as it deals with the systematic correlation between Greenberg \#1 and Greenberg \#8, must be interpreted as a necessary consequence of the law of abbreviation: the set of linguistic items which can be linked by means of a paradigmatic, semantic, or otherwise defined opposition within a given language system will, in any case, be a subset of the total of logically possible pairings of linguistic items within this language system. Much of the fascination of markedness stems from the fact that the correlations addressed in section 2 have always been thought to hold between linguistic items which are paradigmatically, semantically, or otherwise connected, and thus form natural oppositions. This property of markedness appears far less mysterious as soon as markedness can be identified as a corollary of a higher-order principle in the organization of human language such as the law of abbreviation, which affects all linguistic items contained in a given language system. 


\subsection{Method and analysis}

19 To back up these statements with empirical data, the following experiment has been conducted. Three text corpora ranging in length between about 1700 and 22000 words were compiled either by asking native speakers to produce autobiographical materials or similar texts in written form, or by tape-recording and transcribing such texts directly. The languages investigated are Armenian (Indo-European language family), Thai (Daic language family), and Lakota (Siouan language family). Only grammatical items were included in the list of linguistic items used for the experiment, whose results underscore the assumption that the markedness tenet "high discourse frequency correlates with low structural complexity, and vice versa" applies, by and large, to all linguistic items contained in a given language system. In practice, markedness theory focuses on the properties of grammatical items, rather than those of lexical items -- consequently, to substantiate the claim that markedness theory needs to be integrated into the Zipfian framework, grammatical items should be investigated in the first place. Limiting the database to grammatical items this way does not introduce any bias into the data. If the law of abbreviation indeed captures a powerful regularity within language systems, any random set of linguistic items from a given language can be expected to yield the same results with respect to the interdependence of the parameters of frequency and structural complexity: on the whole, the more frequent items will be the less complex ones. This should be true regardless of whether the linguistic items investigated are taken from grammar or from the lexicon, or from both. In a preliminary study which preceded this project, a combined sample of lexical and grammatical items from the Lakota corpus was analyzed. The results, which will not be reproduced here, bear out this prediction.

20 However, a systematic assessment of the applicability of Zipfian principles specifically to grammar is necessitated not only by the nature of the present project. Such a study is of considerable theoretical interest in its own right. The question of whether Zipfian principles are operative in grammatical systems should be of fundamental relevance for any theory of grammar, but it has never been raised. Zipf's particular methodological approach to discourse analysis has probably done a lot to encourage this neglect. The major drawback of Zipf's method from this perspective is its insensitivity to the internal morphological structure of words, on the one hand, and to the semantic individuality of linguistic items, on the other. In most cases, Zipf merely counted words, irrespective of their morphological composition; differences in the meaning of phonetically identical linguistic items are equally irrelevant in Zipf-style analyses.

21 The following example from English illustrates Zipf's analytical method. The form show-s is ambiguous between a nominal and a verbal reading. show-s can, for one, be analyzed as the plural form of the noun show; but show-s is also the third person singular present of the verb to show. In a classical Zipfian discourse analysis, all occurrences of the form show-s are added up in the count as instances of the occurrence of a single linguistic unit, regardless of whether show-s has a nominal or a verbal meaning in individual cases. Since, further, morphologically complex word forms are left unsegmented in classical Zipfian analyses, words are always counted as a whole. Thus, in the case of shows, instead of the morphological units show- and $-s$, only the complex word form shows enters a classical Zipf-style analysis as a countable unit.

22 Grammatical items, however, exhibit a strong tendency to figure as affixes, rather than as free elements. Consequently, this method of counting, which has been adopted by Zipf's successors (e.g., Balasubrahmanyan \& Naranan, 1996), targets only part of the grammatical inventory of a given language, and captures grammatical items only in cases in which they constitute separate words, such as the English definite article the. The percentage of grammatical items that end up in a classical Zipf-style analysis depends on the morphological type of the language in question. The more synthetic a language is, the fewer grammatical items will be captured; the more isolating a language is, the more grammatical items will be included in the analysis. Thus, by means of Zipf's method, the behavior of the 
full inventory of grammatical items which occur in a given text corpus can be assessed only for a perfectly isolating language.

23 In analyzing the discourse data compiled for the purpose of this study, Zipf's method is modified with respect to the above issues. For one, to make sure that grammatical items are targeted systematically, all complex word forms are segmented into their morphological components. In this type of analysis, the English lexeme letter, when occurring as a component of the plural form letter-s, is counted separately from the element $-s$ 'plural'. Occasionally, Zipf employed analyses which incorporate morphological segmentation as well, but the details of these analyses remain too obscure to use them as proof for the validity of Zipfian principles in grammar. Secondly, in the analysis of the Armenian, Thai, and Lakota corpora, homonymy relations between linguistic items are not ignored, as they were in Zipf's methodological approach. Thus, phonetically identical elements are treated as separate linguistic items if the meanings they convey are dissimilar. On these grounds, the English roots ring 'circular object or structure' and ring 'to make the sound of a bell, call on the phone', for instance, must be analyzed as distinct elements.

24 Further, phonetically similar elements exhibiting the same phonemic complexity, i.e. the same number of phonemes, are treated as a single linguistic item if they are synonymous and if the phonetic divergence is merely due to regular phonological or morphonological processes. This relationship holds between the English plural suffixes $[-z]$ and $[-s] ;[-z]$ appears after voiced sounds, as in gull-s $[g \wedge l-z]$, while $[-s]$ is used after voiceless consonants, as in cat-s [kæt-s]. It could, further, be argued that the feature [+voiced], which is present in the consonant constituting the $[-z]$-variant of the English plural morpheme, adds on to the phonemic complexity of this element, as compared to the voiceless alternant $[-s]$. In a more fine-grained analytical approach, variation in the complexity of phonemes originating at the sub-phonemic level might, of course, be taken into account; the nature of the phonological features involved may have an impact on the values for the overall complexity of individual phonemes. This analytical option will, however, be left to future research. The present paper is to be taken as a pilot study which, for the first time, explores the viability of the method outlined above.

25 The structural complexity of individual linguistic items is determined by counting the phonemes they are composed of. Needless to say, the transcript used as the basis of phoneme counts is phonemic in all cases. Traditional orthographies often represent individual phonemes by more than a single symbol. An example is the English past tense suffix -ed in forms such as talk-ed, which has to be rendered by $[-t]$ in a phonemic transcription. There are, of course, various methods of counting phonemes, especially with regard to the question of how sounds with articulatory features such as aspiration, glottalization, and nasalization should be analyzed. For instance, Armenian has a triple series of voiceless stops, which distinguishes the features plain vs. aspirated vs. glottalized. In a more fine-grained phonetic analysis, it is certainly possible to differentiate these with respect to their relative complexity. Thus, glottalized and aspirated consonants should be more complex than plain ones. This entails the additional question of what value of numerical complexity should be ascribed to more complex stops -- should they be counted as biphonemic? To circumvent such analytical complications, a simple, less fine-grained, analysis is chosen for the purpose of this study: all three types of stops are classed as monophonemic. This also goes for nasalized vowels and for affricates. The glottal stop that obligatorily precedes any word-initial vowel is counted as a separate phoneme. In Thai, the contrast between long and short duration of vowels is a distinctive feature. Long vowels are counted as biphonemic, while short ones are counted as monophonemic.

26 To illustrate the analytical method described above, the full list of grammatical items contained in the Thai corpus is given in the appendix. In columns 3 and 4 in the appendix, for each of the 73 grammatical items occurring in the Thai corpus investigated, the respective numerical values for structural complexity (measured in phonemes) and discourse 
frequency are given. To determine whether the variables of discourse frequency and structural complexity do indeed correlate in the three corpora investigated, the average discourse frequency of each group of linguistic items, as defined by their structural complexity or length in phonemes, is calculated in table 2. For this purpose, the frequencies of all items in a given complexity group are added up, and the resulting values (F) are divided by the number of group members (M). F/M yields the average frequency value for each of these groups. ${ }^{2}$

Table 2. Discourse frequency and phonemic complexity of grammemes in Armenian, Thai, and Lakota

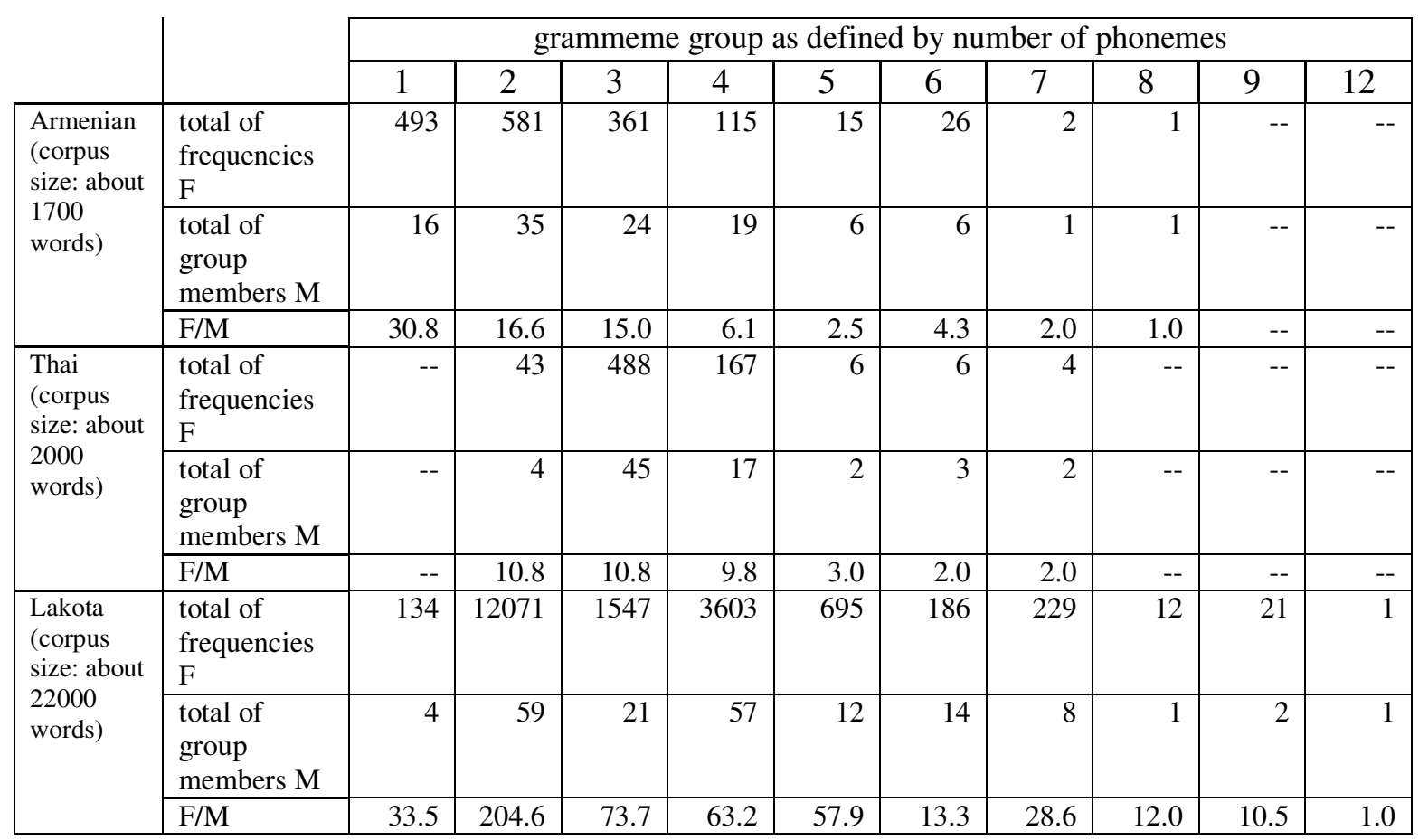

27 In all three languages investigated, on the whole, the average frequency of grammatical items, as represented by the F/M figures, increases as their structural complexity decreases. Analogous analyses which substantiate the correlation between discourse frequency and structural complexity are presented in Zipf (1949/1965b: 64). It should be noted that this type of analysis does not usually yield distributions which are as clearly hyperbolic as the output of rank-based analyses, which are discussed in section 1 and below.

28 Rank-based analyses in which ranking is based on frequency, without taking the variable of structural complexity into account, are among the most popular types of Zipfian analysis. Linguistic or other items are rank-ordered according to their frequency values by means of the following method:

"... one can consider the words of a vocabulary as ranked in the order of their frequency e.g. the first most frequent word, the second most frequent, the third most frequent, the five-hundredth most frequent, the thousandth most frequent, etc. We can indicate on the abscissa of a double logarithmic chart the number

\footnotetext{
${ }^{2}$ Note that the groups characterized by the complexity values 10 and 11 are missing in all three corpora.
} 
of the word in the series and on the ordinate its frequency. Thus, in Eldridge's English count, the most frequent word occurs 4290 times, and is represented by 1 on the abscissa and 4290 on the ordinate; the second word is 2122 and is represented by 2 on the abscissa and 2122 on the ordinate. The words from 239 through 253 each occur 19 times, hence from 239 through 253 on the abscissa the ordinate is 19 , and this group of words of like frequency would appear on the chart as a straight line running at 19 on the ordinate from 239 to 253 on the abscissa." (Zipf, 1935/1965a: 44-45)

29 Such "rank-frequency analyses", just like the rank-based analyses operating with structural complexity which are addressed in section 1, produce the characteristic Zipfian hyperbolas. The hyperbolas are converted into more or less straight lines when the double logarithmic grid Zipf mentions in the above quote is used. The raw discourse data on Armenian, Thai, and Lakota, which have been processed in tables 2 to 4, can, of course, also be used as the basis for rank-frequency analyses. Since this type of analysis is not concerned with correlating discourse frequency with structural complexity, it could, theoretically, be neglected in the context of the present study. Nevertheless, in Figures 2 to 4, rank-frequency analyses of the Armenian, Thai, and Lakota data have been conducted, the result being "genuine" Zipfian hyperbolas:

Figure 2. Rank-frequency analysis of the Armenian corpus

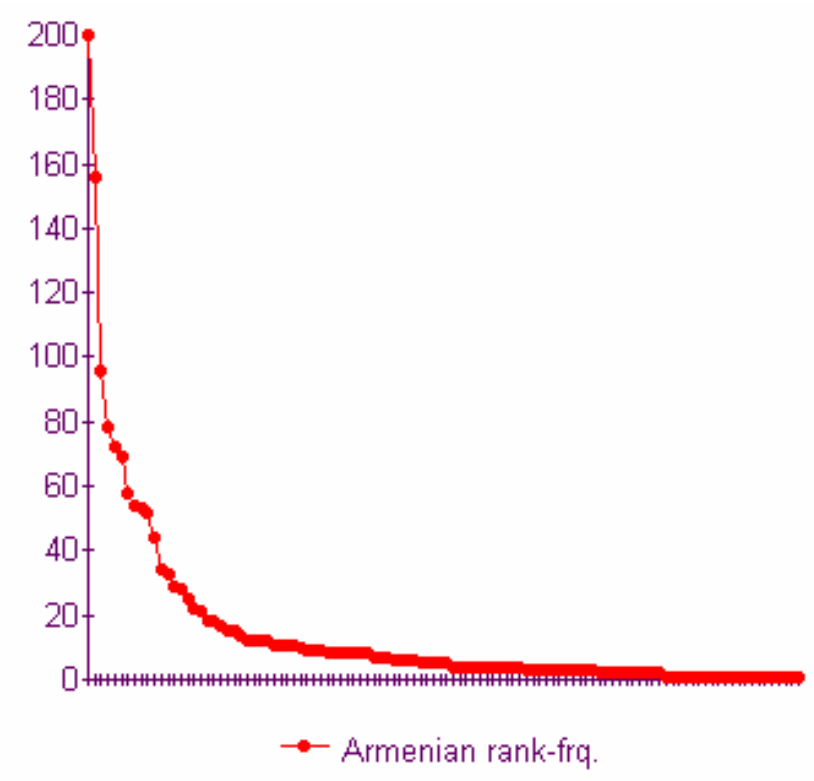

Figure 3. Rank-frequency analysis of the Thai corpus 


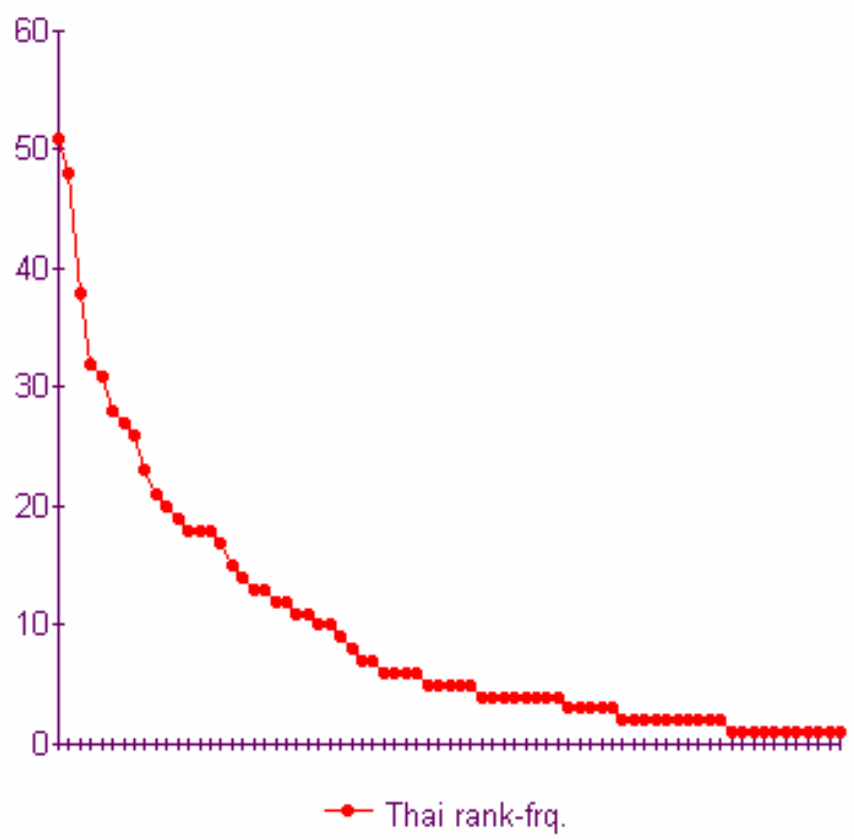

Figure 4. Rank-frequency analysis of the Lakota corpus

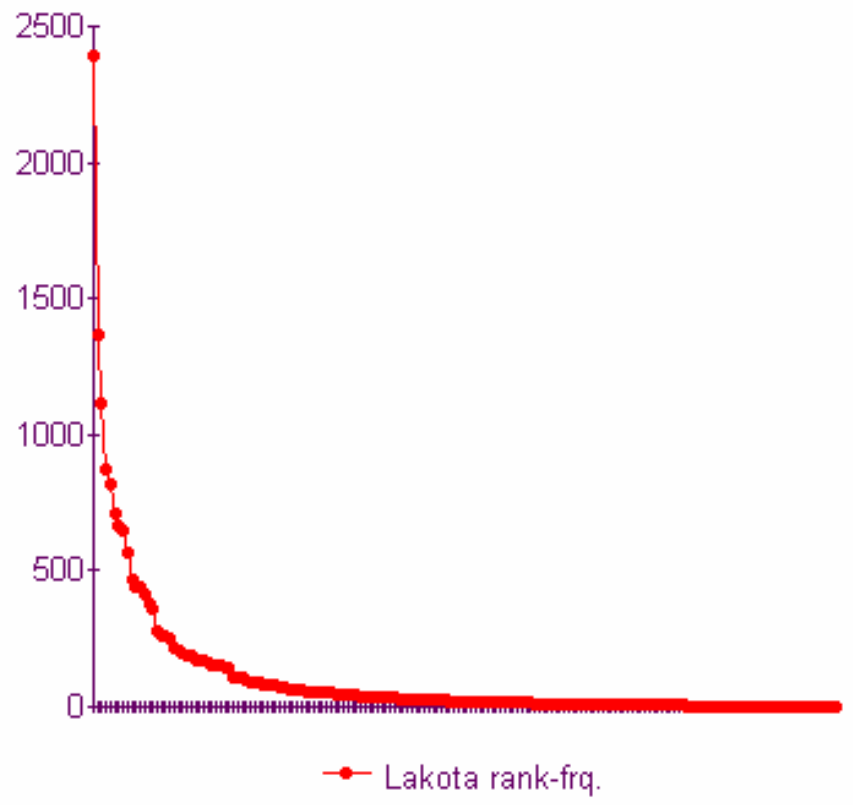

30 The Thai curve can be reproduced by the reader by means of the frequency data given in the appendix.

31 On the basis of the above analyses, in which, for the first time, only grammatical items are taken into account, it can be concluded that grammatical systems do indeed comply with Zipfian principles. Thus, in particular, the general rule of thumb "the shorter, the more frequent" is as valid within grammar as anywhere else in human language. But if this strong correlation between the variables of discourse frequency and structural complexity obtains 
within a discourse corpus as a whole, it can also be expected to hold between the members of random grammeme pairs picked from a list like the one reproduced in the appendix. In other words, it can be predicted that within such chance pairings of grammemes, the grammeme which displays the higher frequency value will, in the majority of cases, also show the lower complexity value. To test this prediction on the Armenian, Thai, and Lakota data, random pairs of grammemes are formed by means of a web-based random number generator (www.random.org). In order to use this technical format for the grammemes under investigation, individual grammemes are made identifiable by numbering them consecutively, as is done for the Thai data in the rightmost column in the appendix. Next, the random number generator is set to creating two columns of numbers (between 1 and 73 for Thai since the Thai grammeme list contains 73 items) via the integer mode; each horizontal row, then, represents a random grammeme pair. For Thai, the first three rows yielded the following grammeme pairs:

Table 3. The first three grammeme pairs of the Thai experiment

$$
\text { gloss } \quad \text { discourse length in }
$$

frequency phonemes

\begin{tabular}{|l|l|r|r|}
\hline nai & in, inside, within & 11 & 3 \\
\hline ca & FUTURE, INTENTIONAL & 32 & 2 \\
\hline
\end{tabular}

\begin{tabular}{|c|c|c|c|}
\hline kæ: & you, he, she & 1 & 3 \\
\hline k'うั:ク & POSSESSIVE, of & 14 & 4 \\
\hline
\end{tabular}

\begin{tabular}{|l|l|r|r|}
\hline$k æ:$ & you, he, she & 1 & 3 \\
\hline$k^{h} \boldsymbol{t}:$ & COPULA & 2 & 3 \\
\hline
\end{tabular}

32 The first pair -- nai 'in, inside, within' (11 occurrences, 3 phonemes) vs. ca 'FUTURE, INTENTIONAL' (32 occurrences, 2 phonemes) -- conforms with the law of abbreviation, which predicts that the more frequent item is structurally less complex than the less frequent item. The second pair, i.e. $k æ$ : 'you, he, she' (1 occurrence, 3 phonemes) vs. $k^{h} \check{\jmath}: \eta$ 'POSSESSIVE, of' (14 occurrences, 4 phonemes), on the other hand, reverses the law of abbreviation.

33 The purpose of this experiment is finding out whether the law of abbreviation produces quantitative correlations between discourse frequency and structural complexity within random pairs of grammatical items. This, however, amounts to verifying whether the law of abbreviation creates markedness effects within random pairs of grammatical items. Each of the random grammeme pairs obtained by means of the above method can be interpreted as a "fake" opposition of linguistic elements. The next step in carrying out the experiment is compiling a reasonably large set of random oppositions which can be used as a basis for a statistical analysis which reveals whether pairs like nai 'in, inside, within' vs. $c a$ 'FUTURE, INTENTIONAL', which are in line with Zipf's model and markedness theory, do in fact outnumber pairs like $k æ$ : 'you, he, she' (1 occurrence, 3 phonemes) vs. $k^{h} \check{\jmath}: \eta$ 'POSSESSIVE, of', which are to be treated as counterexamples to both theoretical models, in the Thai corpus. 
34 The third pair in table 2 -- $k æ x:$ 'you, he, she' ( 1 occurrence, 3 phonemes) vs. $k^{h} t:$ 'COPULA' ( 2 occurrences, 3 phonemes) -- illustrates a constellation in which both members exhibit the same structural complexity. Neither such pairs, nor pairs whose members show identical frequency values, are included in the statistical analyses presented in table 4 since they do not contribute anything to either refuting or confirming the hypothesis that markedness effects occur within random pairs of linguistic items as well.

Table 4. The quantitative correlation between discourse frequency and phonemic complexity of grammemes in Armenian, Thai, and Lakota

\begin{tabular}{|c|c|c|c|}
\hline & & $\begin{array}{l}\text { item with higher } \\
\text { discourse frequency has } \\
\text { lower structural } \\
\text { complexity } \\
\text { (= frequency- } \\
\text { complexity correlation } \\
\text { confirmed) }\end{array}$ & $\begin{array}{l}\text { item with higher } \\
\text { discourse frequency } \\
\text { has higher structural } \\
\text { complexity } \\
\text { (=frequency- } \\
\text { complexity } \\
\text { correlation refuted) } \\
\end{array}$ \\
\hline \multirow[t]{2}{*}{ Armenian } & $\begin{array}{l}\text { number of valid pairs in } \\
\text { a total of } 200 \text { pairs }\end{array}$ & 103 & 41 \\
\hline & $\begin{array}{l}\% \text { of valid pairs in total } \\
\text { of valid pairs }\end{array}$ & $71.5 \%$ & $28.5 \%$ \\
\hline \multirow[t]{2}{*}{ Thai } & $\begin{array}{l}\text { number of valid pairs in } \\
\text { a total of } 200 \text { pairs }\end{array}$ & 75 & 25 \\
\hline & $\begin{array}{l}\% \text { of valid pairs in total } \\
\text { of valid pairs }\end{array}$ & $75.0 \%$ & $25.0 \%$ \\
\hline \multirow[t]{2}{*}{ Lakota } & $\begin{array}{l}\text { number of valid pairs in } \\
\text { a total of } 200 \text { pairs }\end{array}$ & 100 & 42 \\
\hline & $\begin{array}{l}\% \text { of valid pairs in total } \\
\text { of valid pairs }\end{array}$ & $70.4 \%$ & $29.6 \%$ \\
\hline
\end{tabular}

\subsection{Conclusions}

35 The percentages calculated in table 4 demonstrate that in the Armenian, Thai, and Lakota corpora, due to the constraints imposed by the law of abbreviation, the chance of obtaining random pairings of grammemes in which the more frequent member is the structurally less complex is up to three times as high as the chance of obtaining grammeme pairs in which the more frequent member is the structurally more complex. ${ }^{3}$ Thus, the startling outcome of

\footnotetext{
${ }^{3}$ Chi-square analyses of the data presented in table 4 show that in all three languages, the threshold value for statistical significance ( 3.84 for $\mathrm{p}=0.5)$ is clearly exceeded.
} 
the above experiment is that in comparing values for discourse frequency and structural complexity, it is irrelevant what linguistic items are grouped together -- pairs in which higher discourse frequency is coupled with lower structural complexity, and vice versa, will prevail. In other words, the predominance of the correlation between higher frequency with lower structural complexity, whose discovery ranks among the most noteworthy achievements of markedness theory, can be observed outside of natural oppositions as well. Randomly generated pairs of linguistic items and the natural oppositions markedness theory is based on produce the very same markedness relations. But this certainly comes as no
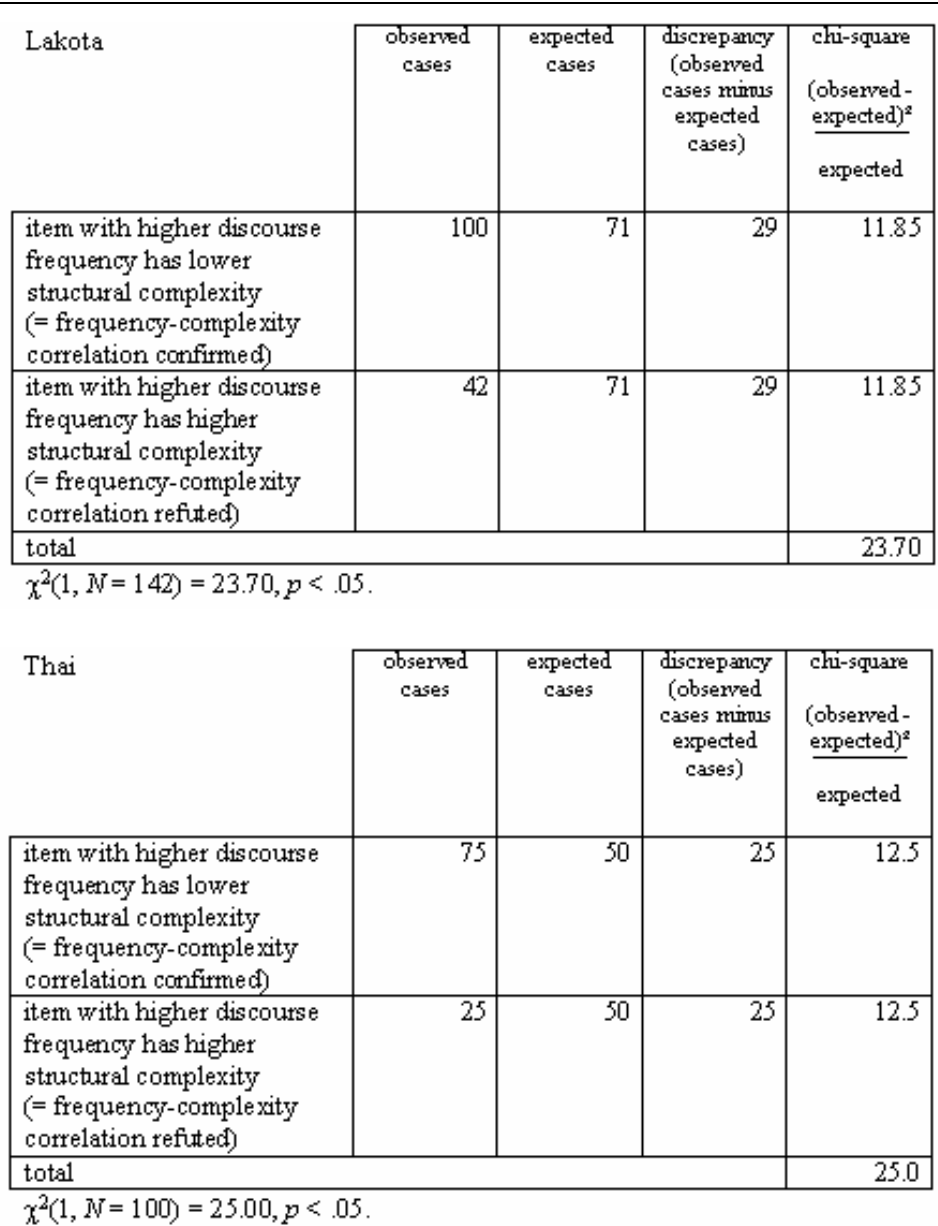

\begin{tabular}{|c|c|c|c|c|}
\hline Atmletriati & $\begin{array}{c}\text { obsemed } \\
\text { cases }\end{array}$ & $\begin{array}{l}\text { expected } \\
\text { cases }\end{array}$ & $\begin{array}{l}\text { digcrepangy } \\
\text { cobsemed } \\
\text { cases minus } \\
\text { expected } \\
\text { cases) }\end{array}$ & $\begin{array}{l}\text { ahi-square } \\
\text { (observed - } \\
\text { expected) } \\
\text { expected }\end{array}$ \\
\hline $\begin{array}{l}\text { item with higher dis coutse } \\
\text { frequetiog has lower } \\
\text { structural complexity } \\
\text { (= frequency-complexity } \\
\text { correlation confirtued }\end{array}$ & 103 & 72 & 31 & 13.35 \\
\hline $\begin{array}{l}\text { item with higher dis course } \\
\text { frequenoy has higher } \\
\text { sttuctural cotholexity } \\
\text { (= frequenoy-complexity } \\
\text { cortelation refuted }\end{array}$ & 41 & 72 & 31 & 13.35 \\
\hline \multicolumn{4}{|l|}{ Total } & 26.70 \\
\hline
\end{tabular}


surprise if the law of abbreviation is taken to be effective in the organization of discourse structure.

36 On these grounds, the law of abbreviation can be identified as the causal backdrop of markedness phenomena, at least as far as the systematic correlation between the morphosyntactic markedness criteria Greenberg \#1 (structural complexity) and Greenberg \#8 (discourse frequency) is concerned. Any language which complies with the law of abbreviation -- that is, presumably, every language --, will yield results which are analogous to those obtained for Armenian, Thai, and Lakota.

37 As an interesting refinement of the approach taken in this study, the correlation between structural complexity and discourse frequency could, additionally, be tested on the basis of grammatical oppositions only, i.e. within the classical domain of markedness theory. If the resulting percentage of constellations which confirm markedness theory roughly equals the percentage of analogous constellations obtained for the overall text corpus analyzed for a given language, it must be concluded that the principles responsible for the preponderance of constellations which support markedness theory within oppositions are identical to the principles which are at work in the overall text corpus.

38 Even in the (unlikely) event that the investigation of oppositions yields a drastically higher value for the constellations which are in line with markedness theory than the overall text corpora do, the hypotheses proposed in the present paper hold up. It would be nonsensical to claim that the markedness effects observed within text corpora in which all grammatical items involved are taken into account, and those observed exclusively within oppositions, stem from different sources. This would amount to stating that for some mysterious reason, oppositions form their own micro-universe of statistical laws, in complete isolation from the laws which obviously apply to all other members of the grammatical inventories of a given language. If the figures for constellations which confirm markedness should indeed turn out to be significantly higher in oppositions, the challenge to be met lies in establishing additional principles which motivate the difference.

\section{Motivating the correlation between discourse frequency and structural complexity}

39 Given that the majority of the leading $20^{\text {th }}$ century language theorists have dealt with markedness, it comes as quite a surprise that the obvious parallels between markedness and Zipfian principles have hardly ever been addressed in the extant literature so far. One crucial factor that can be held responsible for obfuscating these connections is Zipf's methodological predilection for counting words without segmenting them into their morphological components, and for ignoring homonymy relations between linguistic items (cf. section 3). Such a procedure, of course, does not provide any insights into the behavior of grammatical items. Since grammar takes center stage in Greenbergian and postGreenbergian markedness theory, Zipf's model was not one of the more likely places to look when motivating markedness phenomena was at issue.

40 In the more recent literature, the possibility of linking morphosyntactic markedness to Zipf's theories is hinted at repeatedly (e.g. Battistella, 1990: 35; Croft, 1990: 156f.; Haiman, 1985: 150; Levinson, 2000: 135ff.), but never explored in full detail. The present paper argues that this connection might be far more profound than hitherto assumed -- faced with the data presented in section 3, one feels tempted to hypothesize that at least one crucial component of the phenomenon of markedness, namely, the correlation between length and frequency, is the inevitable output of Zipfian principles. Consequently, understanding the internal dynamics of Zipf's model would amount to understanding the raison d'être of markedness.

41 According to Zipf, the relationship of frequency and structural complexity is such that the former controls the latter:

"Until it can be shown that lengthenings occur from frequency or shortenings from rarity, we may reasonably presume ... that, where frequency and 
abbreviatory substitution are connected, the frequency is the cause of the abbreviatory substitution." (Zipf, 1935/1965a: 36)

42 So far, the hypothesis of this particular directionality of the causal connection between the two parameters has, apparently, never been called into question. To Zipf (1935/1965a: 29), the reversal of this causality relation, in which structure would figure as the cause and frequency as the effect, is implausible because "on the whole the comparative length or shortness of a word cannot be the cause of its relative frequency of occurrence because the speaker selects his words not according to their lengths, but solely according to the meanings of the words and the ideas he wishes to convey". Thus, "high frequency is the cause of small magnitude" (Zipf, 1935/1965a: 36). In the same vein, Bybee (e.g. 2000: 72) identifies frequency increase as the motivation of the structural reduction of linguistic items in language change: "The more a word is used ... the more reduced the word becomes."

43 The crucial notion which establishes a causal connection between the parameters of frequency and structural complexity is Zipf's principle of least effort. Throughout his work, Zipf uses the principle of least effort to explain the statistical correlations he discovered in human language and beyond. Speaking is an activity which consumes energy. According to Zipf, biological organisms strive to spend as little energy as possible. Zipf argues that in speaking, a considerable amount of energy can be saved if linguistic units that are used very often are kept shorter than those which are used less frequently. Thus, discourse frequency, via the mediating principle of least effort, alias economy, controls the structural complexity of linguistic items. Of course, both speaker and hearer play a role in the creation of structurally reduced forms. A reduced form is an effective means of communication only if it is accepted by the hearer as a usable linguistic item (B. Joseph, p.c.). The importance of the economy principle is underscored by the fact that it is manifested at various additional levels of speech production and processing, such as Grice's maxims. From a more general point of view, the approach proposed in the present study is compatible with functional, typological, and usage-based models of language as exemplified by works such as Bybee (1985), Croft (1990), and Hawkins (2004). A comparable empirical investigation, however, has not yet been carried out.

44 It should be noted that so far, attempts at motivating the correlation between frequency and structural complexity seem to have attracted more attention in linguistics than anywhere else. Past and ongoing research in the numerous "hard" sciences which work with Zipf's Law is more concerned with verifying its validity via a multitude of empirical investigations. Thus, in these disciplines, insofar as statements pertaining to this issue are available at all, the economy principle is not necessarily regarded as an explanation for Zipf's Law and for its various manifestations, such as the law of abbreviation (Gell-Mann, 1994: 97: "Zipf's law remains essentially unexplained"). But no matter what the ultimate explanation for Zipf's Law may be, at this point, it is safe to say that Zipf's model provides the opportunity of embedding a crucial aspect of the phenomenon of markedness into a more general scientific context.

\section{Markedness and Zipf's model of language: beyond frequency and structural complexity}

45 In the preceding sections, a hitherto unexplored but cogent way of motivating markedness phenomena, in particular, the well-known correlation between the structural complexity and discourse frequency of linguistic items, has been proposed. The latter parameters can be regarded as basic components of both markedness theory and Zipf's model of language. Research within the Zipfian framework discloses a systematic covariance of discourse frequency and structural complexity, which includes all elements which are part of a given language system. As a rule, higher discourse frequency of individual linguistic items is coupled with lower structural complexity; lower discourse frequency, on the other hand, tends to be coupled with higher structural complexity. This formula coincides with the claims markedness theory makes about the properties of linguistic items which stand in 
some kind of semantically, paradigmatically, or otherwise defined opposition. If, however, as Zipf's theories maintain, this correlation applies to any linguistic item within a given language system, it is, inevitably, effective within any randomly chosen pair of linguistic items as well. As a result, the more frequent member of the pair is very likely to exhibit lower structural complexity than the less frequent member. The validity of this claim is substantiated by the analysis of discourse data from Armenian, Thai, and Lakota, which demonstrate that random combinations of grammemes produce markedness relations significantly more frequently than they produce constellations which are not in line with markedness theory. The occurrence of markedness effects becomes predictable if Zipf's model of language is rescued from near-oblivion, and if Zipf's analytical method is modified as suggested in section 3 .

46 Markedness is a vast area of research; it is tempting to speculate on how further -- possibly all -- aspects of markedness could be motivated in the context of Zipf's model. Beyond frequency and structural complexity, various additional issues which contribute to markedness theory are addressed in Zipf's work. For instance, Zipf's (1935/1965a) data on phonology seem to indicate that phonological markedness abides by the same rules as morphosyntactic markedness. Zipf (1949/1965b: 120) also hypothesizes that there is a correlation between the relative age of linguistic items and their frequency and structural complexity. The correlation is such that it supports current approaches to markedness which maintain that diachronic change proceeds from unmarked to marked items (e.g. Andersen, 2001a). In future research on markedness, it might also be worthwhile to verify whether semiotic, cognitive, and even cultural aspects of markedness can be fruitfully connected with Zipf's model. Another rewarding topic might be the investigation of context-dependent markedness phenomena such as markedness assimilation (e.g. Andersen, 1972) and markedness reversal (e.g. Tiersma, 1982) from a Zipfian perspective.

47 Last but not least, both Zipf's model and markedness theory deal with the issue of the complexity of meaning of linguistic items; semantic complexity is claimed to stand in a correlative relationship to other basic parameters, among them discourse frequency and structural complexity. To substantiate this hypothesis at least for lexical items, Zipf counted dictionary translations for individual linguistic elements. Needless to say, from today's perspective, this empirical procedure will hardly be considered a satisfactory tool in determining semantic complexity. Yet its application to his data led Zipf (1949/1965b: 28) to establish a correlation between high frequency and a large number of meanings, and vice versa, between low frequency and a small number of meanings. As is to be expected on the basis of the law of abbreviation, linguistic items that exhibit a large number of meanings, in general, are also found to be structurally less complex than those which have fewer meanings.

48 More recent evidence for the empirical reality of the correlation of the three parameters frequency, structural complexity, and semantic complexity comes from Levinson (2000: 137ff.), who, on investigating data from all kinds of structural domains, observes that items of higher structural complexity tend to be less frequent and semantically more specialized:

"On the formal side, marked forms, in comparison to corresponding unmarked forms, are more morphologically complex and less lexicalized, more prolix or periphrastic, less frequent or usual, and less neutral in register. On the meaning side, such forms suggest some additional meaning or connotation absent from the corresponding unmarked forms."

49 Similarly, Haiman (1980: 528) argues that "increased morphological complexity is an icon of increased semantic complexity"; Andersen (2001b: 47-48) characterizes marked items as "semantically more complex" than their unmarked counterpart, and as having "more semantic features" and thus "greater intension" and "lesser extension".

50 Zipf's criterion of "large vs. small number of meanings" is tantamount to Andersen's concept of extensional complexity. In contrast, Levinson's and Haiman's statements pertain to the intensional complexity of semantic concepts. Levinson's and Haiman's approaches, unlike 
Zipf's, operate on the basis of a decomposition of concepts into semantic features. Since, however, the low extensional complexity assigned to items of high structural complexity in Zipf's model is concomitant with high intensional complexity, Zipf's observations are in line with Levinson's and Haiman's claims regarding the high intensional complexity of structurally complex, or marked, linguistic items. Thus, Zipf's work clearly supports the basic assumptions of current approaches to iconicity.

51 Taking the parameter of semantic complexity into account, however, points to additional explanatory options in the attempt to motivate the correlation between frequency and structural complexity of linguistic items. According to Andersen (2001b: 50), discourse frequency is a dependent variable which is determined by, and thus epiphenomenal to, the variable of semantic complexity:

"... since marked terms have lesser reference potential (or more narrowly defined privileges of occurrence) than their unmarked counterparts, their frequency is lower." (Andersen 2001b: 50)

52 On these grounds, elaborating on what is said in section 4, an extended model can be postulated, in which the parameter of structural complexity, via discourse frequency as an economy-driven mediating link, is controlled by semantic complexity. However, adopting this model, ultimately, does not have any impact on the most basic claim made in this study: the data presented in section 3 show that morphosyntactic markedness relations do not only hold between members of linguistic oppositions, but rather, between all members of individual grammatical systems. Thus, markedness phenomena will not only manifest themselves when components of a single grammatical paradigm are compared, such as, for instance, markers for the first and second person. They also exist between randomly chosen grammatical items such as a first person marker and an imperfective marker, or an object marker, or a question marker, etc. If the variable of semantic complexity is included in the model, and the respective values for semantic complexity reflect the predictions made in the above quotes, these values can be assumed to co-vary with the ones obtained for discourse frequency and structural complexity in such a way that random pairings of grammatical items in which semantic complexity is contrasted with either frequency or structural complexity produce statistical asymmetries which are equivalent to those which substantiate the correlation between frequency and structural complexity. Unfortunately, given the empirical methods available today, it is extremely difficult, if not impossible, to measure semantic complexity (Croft, 1990: 170f.). Quantification of frequency and structural complexity, on the other hand, is easy and uncontroversial. For this reason, the empirical investigations described in section 3 have been conducted on the basis of the parameters of frequency and structural complexity alone.

53 The conclusion that results from reconsidering markedness in the context of Zipf's model of language is that grammatical systems -- and presumably lexical inventories as well -- are hierarchically organized in terms of at least three parameters: discourse frequency, structural complexity, and semantic complexity. Quantitative values such as frequency figures and length in phonemes determine the position of individual linguistic items in the respective hierarchies, and consequently, the position of any linguistic item contained in the system relative to any other linguistic item which is part of this system. The fact that the hierarchies are interdependent to the extent that regularities such as the law of abbreviation can be stated, further, creates markedness phenomena. The fact that the above hierarchies correlate may define one of the most profound organizing principles of human language: the empirical data presented in section 3 indicate that for the combined parameters of frequency and structural complexity, random pairings of grammatical items produce constellations which comply with markedness theory up to three times as often as constellations which refute markedness theory. Thus, the markedness effects observed in the highly specialized environment of grammatical oppositions merely constitute a small fraction of the logical constellations supporting markedness theory that result from the law of abbreviation. 


\section{Appendix}

Discourse frequency and phonemic complexity of grammemes in the Thai corpus (about 2000 words)

The glosses exclusively represent the usages encountered in the text corpus investigated, and may therefore be partial.

$$
\text { gloss } \begin{gathered}
\text { discourse length in \# } \\
\text { frequency phonemes }
\end{gathered}
$$

\begin{tabular}{|c|c|c|c|c|}
\hline$a_{i}: t$ & may, might & 4 & 4 & 1 \\
\hline bai & NUMERAL CLASSIFIER for flat or round things & 1 & 3 & 2 \\
\hline$c a$ & FUTURE, INTENTIONAL & 32 & 2 & 3 \\
\hline cá & HONORIFIC: polite, intimate social context & 2 & 2 & 4 \\
\hline cà:k & from, since & 6 & 4 & 5 \\
\hline con & so (that), until, as far as & 2 & 3 & 6 \\
\hline chăn & I & 26 & 3 & 7 \\
\hline dannân & so, thus, therefore & 3 & 6 & 8 \\
\hline dĭau & when, then, otherwise & 3 & 4 & 9 \\
\hline dúai & $\begin{array}{l}\text { with (COMITATIVE), also, too, as, let, together, due } \\
\text { to, because of, ADVERBIALIZER }\end{array}$ & 6 & 4 & 10 \\
\hline ə̆:i & INTERJECTION: familiarity, affection & 1 & 4 & 11 \\
\hline hái & BENEFACTIVE & 11 & 3 & 12 \\
\hline hwà: & COMPARATIVE, rather & 10 & 4 & 13 \\
\hline jâm & EMPHASIS & 1 & 3 & 14 \\
\hline jín & more than & 3 & 3 & 15 \\
\hline jù: & CONTINUOUS & 4 & 3 & 16 \\
\hline kamlan & $\begin{array}{l}\text { PROGRESSIVE, CONTINUOUS, IMMEDIATE } \\
\text { FUTURE }\end{array}$ & 2 & 6 & 17 \\
\hline kan & RECIPROCAL, PLURAL, together & 13 & 3 & 18 \\
\hline$k a ̀ p \square$ & and, with, on, to, at, against & 7 & 3 & 19 \\
\hline kæ: & you, he, she & 1 & 3 & 20 \\
\hline kó: & and, then, subsequently, afterwards, also, still & 48 & 3 & 21 \\
\hline$k^{h} a ̆ u$ & he, she, they & 15 & 3 & 22 \\
\hline$k^{h} O \eta$ & may, maybe, probably, surely & 4 & 3 & 23 \\
\hline$k^{h} \check{0}: \eta$ & POSSESSIVE, of & 14 & 4 & 24 \\
\hline$k^{h i ́ n}$ & up & 4 & 3 & 25 \\
\hline$k^{h} \dot{t}:$ & COPULA & 2 & 3 & 26 \\
\hline lá? & QUESTION, IMPERATIVE & 1 & 3 & 27 \\
\hline là? & COMPLETIVE & 1 & 3 & 28 \\
\hline |æ่? & INTENSIFIER & 9 & 3 & 29 \\
\hline
\end{tabular}




\begin{tabular}{|c|c|c|c|c|}
\hline læ̂? & and & 6 & 3 & 30 \\
\hline lஜ̂:u & consequently, and, then & 4 & 4 & 31 \\
\hline læê:u & COMPLETIVE, already & 28 & 4 & 32 \\
\hline læe:ukó: & and then & 3 & 7 & 33 \\
\hline lø:i & past, beyond, further on, too, consequently & 27 & 4 & 34 \\
\hline mái & NEGATIVE & 51 & 3 & 35 \\
\hline $\operatorname{man}$ & it & 18 & 3 & 36 \\
\hline ma: & at & 17 & 3 & 37 \\
\hline má:ko & INTENSIFIER, a lot, more & 18 & 4 & 38 \\
\hline ná/nâ & COMPLEMENTIZER & 4 & 2 & 39 \\
\hline ná/nâ & IMPERATIVE & 5 & 2 & 40 \\
\hline nai & in, inside, within & 11 & 3 & 41 \\
\hline năi & QUESTION & 1 & 3 & 42 \\
\hline nán & DISTAL DEMONSTRATIVE: that & 7 & 3 & 43 \\
\hline nâ?/ná? & IMPERATIVE & 2 & 3 & 44 \\
\hline ná: & should, ought to, probably, quite & 5 & 3 & 45 \\
\hline nína: & HONORIFIC: neutral politeness level & 1 & 5 & 46 \\
\hline ni: & PROXIMATE DEMONSTRATIVE: this & 1 & 3 & 47 \\
\hline nî: & PROXIMATE DEMONSTRATIVE, here, thus & 23 & 3 & 48 \\
\hline$j: k$ & out, from, off & 10 & 4 & 49 \\
\hline pen & COPULA & 18 & 3 & 50 \\
\hline$p^{h}$ o: & when, then & 5 & 3 & 51 \\
\hline$p^{h} r \hat{\jmath} ?$ & because of & 12 & 4 & 52 \\
\hline rau & I, we & 19 & 3 & 53 \\
\hline rò:? & sentence-final particle, informal & 5 & 4 & 54 \\
\hline$r \grave{t}$ & or & 2 & 3 & 55 \\
\hline sæ̌:n & so, extremely, very & 2 & 4 & 56 \\
\hline $\operatorname{si}(?)$ & HORTATIVE & 2 & 3 & 57 \\
\hline tàn & since, for (a certain time) & 8 & 3 & 58 \\
\hline tà:nhà: & also, separately, on the contrary & 1 & 7 & 59 \\
\hline tón & must & 20 & 3 & 60 \\
\hline to:n & when & 13 & 4 & 61 \\
\hline tæ: & but, only, merely, since, however, just & 31 & 3 & 62 \\
\hline thân & though & 2 & 3 & 63 \\
\hline thá: & if & 6 & 3 & 64 \\
\hline tha: & she, he, you & 3 & 3 & 65 \\
\hline$t^{\text {th }}$ æ:m & and, moreover & 4 & 4 & 66 \\
\hline thi: & at, in, to, for, because, on & 12 & 3 & 67 \\
\hline
\end{tabular}




\begin{tabular}{|l|l|r|r|r|}
\hline$t^{t h} \boldsymbol{i}:$ & COMPLEMENTIZER, RELATIVIZER, when & 21 & 3 & 68 \\
\hline $\boldsymbol{t h}^{\text {trn }}$ & $\begin{array}{l}\text { to(wards), as far as, until, about, regarding, to the } \\
\text { extent of, so that, even }\end{array}$ & 4 & 3 & 69 \\
\hline wăi & to be able to & 2 & 3 & 70 \\
\hline wâiwá: & COMPLEMENTIZER & 38 & 3 & 71 \\
\hline wá: & COMPLEMENTIZER & 5 & 5 & 73 \\
\hline wela: & when & 1 & 3 \\
\hline
\end{tabular}

\section{Acknowledgement}

I am indebted to Bernard Comrie for very helpful suggestions on an earlier version of this paper.

\section{References}

ANDERSEN, H. 1972. Diphthongization. Language 48: 11-50.

ANDERSEN, H. 1989. Markedness theory. The first 150 years. In O. M. TOMIC (ed.), Markedness in synchrony and diachrony. Berlin: Mouton de Gruyter: 11-46.

ANDERSEN, H. (ed.) 2001a. Actualization. Linguistic change in progress. Amsterdam: Benjamins. ANDERSEN, H. 2001b. Markedness and the theory of linguistic change. In H. ANDERSEN (ed.): 157.

BALASUBRAHMANYAN, V. K., NARANAN, S. 1996. Quantitative linguistics and complex system studies. Journal of Quantitative Linguistics 3: 177-228.

BATTISTELLA, E. L. 1990. Markedness: the evaluative superstructure of language. Albany: SUNY Press.

BAtTiSTElla, E. L. 1996. The logic of markedness. New York: Oxford University Press.

BYBEE, J. L. 1985. Morphology: a study of the relation between meaning and form. Amsterdam: Benjamins.

BYBEE, J. L. 2000. The phonology of the lexicon: evidence from lexical diffusion. In M. BARLOW, S. KEMMER (eds.), Usage-based models of language.Stanford: CSLI: 65-85.

CHOMSKY, N. 1980. On binding. Linguistic Inquiry 11: 1-46.

Chomsky, N., Halle, M. 1968. The sound pattern of English. New York: Harper \& Row.

COMRIE, B. 1986. Markedness, grammar, people, and the world. In F. ECKMAN, E. A.

MORAVCSIK, J. R. WIRTH (eds.): 85-106.

CROFT, W. 1990. Typology and universals. Cambridge: Cambridge University Press.

CROFT, W. 1991. Syntactic categories and grammatical relations. Chicago, London: University of Chicago Press.

CROFT, W. 2001. Radical construction grammar. Syntactic theory in typological perspective. Oxford: Oxford University Press.

Eckman, F., MoravcsiK, E. A., Wirth, J. R. (eds.) 1986. Markedness. New York: Plenum Press.

Gell-MANN, M. 1994. The quark and the jaguar. New York: Freeman.

GIVÓN, T. 1991. Markedness in grammar: distributional, communicative and cognitive correlates of syntactic structure. Studies in Language 15: 335-370. 
GIVón, T. 1995. Functionalism and grammar. Amsterdam, Philadelphia: Benjamins.

GREENBERG, J. H. 1966. Language universals, with special reference to feature hierarchies. The Hague: Mouton.

HAIMAN, J. 1980. The iconicity of grammar: isomorphism and motivation. Language 56: 515-540.

HAIMAN, J. 1985. Natural syntax. Iconicity and erosion. Cambridge: Cambridge University Press.

HASPELMATH, M. 2006. Against markedness (and what to replace it with). Journal of Linguistics 42: $25-70$.

HAWKINS, J. A. 2004. Efficiency and complexity in grammars. Oxford: Oxford University Press.

HINDS, J. 1988. Japanese. London, New York: Routledge.

JAKOBSON, R. 1932/1984a. The structure of the Russian verb. In L. WAUGH, M. HALLE (eds.), Russian and Slavic grammar studies, 1931 - 1981. Berlin etc.: Mouton: 1-14.

JAKOBSON, R. 1936/1984b. Contributions to the general theory of case: general meanings of the Russian cases. In L. WAUGH, M. HALLE (eds.), Russian and Slavic grammar studies, 1931 - 1981. Berlin etc.: Mouton: 59-103.

JAKOBSON, R. 1939/1984c. Zero sign. In L. WAUGH, M. HALlE (eds.), Russian and Slavic grammar studies, 1931 - 1981. Berlin etc.: Mouton: 151-160.

LASS, R. 1980. On explaining language change. Cambridge: Cambridge University Press.

LEVInSON, S. C. 2000. Presumptive Meanings. The Theory of Generalized Conversational Implicature. Cambridge, Mass.: MIT.

MCCAWLEY, J. D. 1985. Kuhnian paradigms as systems of markedness conventions. In: A. MAKKAI, A. MELBY (eds.), Linguistics and philosophy: studies in honor of Rulon S. Wells. Amsterdam: Benjamins: 23-43.

MoravcsiK, E. A., WIRTH, J. R. 1986. Markedness -- an overview. In: F. ECKMAN, E. A. MORAVCSIK, J. R. WIRTH (eds.): 1-11.

PRINCE, A., SMOLENSKY, P. 1993. Optimality theory: Constraint interaction in generative grammar. Technical Report TR-2, Center for Cognitive Science, Rutgers University, New Brunswick, N.J., and Technical Report CU-CS-696-93, Department of Computer Science, University of Colorado, Boulder.

SHAPIRO, M. 1983. The sense of grammar. Bloomington: Indiana University Press.

SHAPIRO, M. 1991. The sense of change. Bloomington: Indiana University Press.

TIERSMA, P. M. 1982. Local and general markedness. Language 58: 832-849.

TrubetzKoy, N. 1931. Die phonologischen Systeme. Travaux du Cercle Linguistique de Prague 4: 96-116.

ZIPF, G. K. 1935/1965a. The psycho-biology of language. Cambridge, Mass.: MIT.

ZIPF, G. K. 1949/1965b. Human behavior and the principle of least effort. New York, London: Hafner.

To quote this paper :

e-reference: Regina Pustet, On the correlation between discourse frequency and structural complexity in markedness theory, Discours, 5 | 2009 [En ligne], mis en ligne le 04 décembre 2009. URL : http://discours.revues.org/index7683.html. 